\title{
Towards standard methods for the classification of aquatic toxicity for biologically active household chemicals (BAHC) present in plastics, pharmaceuticals, and cosmetic products
}

\author{
Ricardo Beiras
}

Received: 4 March 2021 / Accepted: 30 August 2021 / Published online: 2 October 2021

(C) The Author(s) 2021

\begin{abstract}
A standard method to test the aquatic toxicity of biologically active household chemicals (BAHC), including those with very low water solubility, is proposed. The method uses the common marine models Paracentrotus lividus embryos and Acartia clausi larvae, in order to advance towards derivation of water quality criteria for these emerging pollutants that currently lack environmental standards. Depending on the water solubility and octanol-water partition coefficient $\left(K_{\mathrm{ow}}\right)$ of the substance, the protocol consists of testing the toxicity of the substances by serial dilutions of water stocks, dimethyl-sulfoxide stocks, or $100 \mathrm{mg} / \mathrm{L}$ lixiviates in seawater. When this method is applied to eleven model BAHC, the pharmaceutical fluoxetine, the antioxidant butylated hydroxytoluene, and the UV filters broadly present in cosmetics octocrylene and 4-methylbenzylidene camphor, are classified as very toxic to aquatic life, since their $\mathrm{EC}_{50}$ values are $<1 \mathrm{mg} / \mathrm{L}$. In general, both
\end{abstract}

Supplementary information The online version contains supplementary material available at https://doi. org/10.1007/s10661-021-09436-w.

R. Beiras $(\square)$

Department of Ecology and Animal Biology,

Faculty of Marine Sciences, University of Vigo,

36310 Vigo, Galicia, Spain

e-mail: rbeiras@uvigo.gal

R. Beiras

ECIMAT-CIM, University of Vigo, Illa de Toralla,

36331 Vigo, Galicia, Spain biological models, P. lividus and A. clausi, yield the same classification of the substances tested, but variations in the classification of aquatic toxicity depending on methodological aspects are discussed. The use of A. clausi nauplii provides more protecting value to the toxicity parameters obtained by using this protocol.

Keywords Water quality - Toxicity · Copepods · Echinoderms $\cdot$ Larvae $\cdot$ UV filters

\section{Introduction}

An increasing amount of synthetic chemicals are used to manufacture everyday items such as plastics, textiles, cosmetics, and pharmaceuticals, and for many of them, adverse biological effects on aquatic organisms have been reported [reviewed by Hahladakis et al. (2018) for plastic additives, Samchetshabam et al. (2017) for textiles, Beiras (2021) for cosmetics and pharmaceuticals]. These biologically active household chemicals (BAHC) reach surface waters through urban wastewater effluents and improper environmental disposal. Depuration in wastewater treatment plants rarely removes more than $90 \%$ of the chemical, and the remaining is discharged in the receiving estuarine and coastal waters. Even though most of these chemicals are non-persistent, in practice their continuous input to natural water bodies causes permanent exposure of organisms inhabiting 
receiving waters (Margot et al., 2015). Therefore, the frequent detection of BAHC in surface waters raises emerging concern on their potential ecotoxicological effects on coastal ecosystems (Beiras, 2018).

Plastics have become a ubiquitous feature of modern life, and their global production has risen to the current 359 million tons per year (Plastics Europe and Conversio Market \& Strategy GmbH, 2020), around 50\% for single-use disposable items. Plastics have two different components with very different toxicity and environmental fate: (i) the polymeric matrix consisting of long carbon chains with inert chemical properties, and (ii) a set of lower molecular weight chemicals, normally not bound to the polymer chains, termed functional additives, intentionally added to give the material the desired mechanical properties throughout the product's life. The main plastic additives are plasticizers, flame retardants (e.g., tris 1-chloropropan-2-yl phosphate (TCPP), tris 1,3-dichloro-2-propyl phosphate (TDCP)), UV stabilizers (e.g., chimassorb, CHI), antioxidants (e.g., butylated hydroxytoluene, BHT), and antimicrobials (e.g., lawsone, LAW) (Bolgar et al., 2015; British Plastic Federation, 2021). Conventional polymers are produced by polymerization of olefins by petrochemical companies. These raw materials termed resins are later used for the fabrication of plastic products by adding the desired functional additives in a process termed compounding. Aquatic toxicity studies suggest low toxicity of the precompounding resins (Beiras et al., 2018; Cole et al., 2015; Kaposi et al., 2014; Vroom et al., 2017), whereas commercial plastic products frequently produce toxic leachates (Bejgarn et al., 2015; Lithner et al., 2009, 2012; Oliviero et al., 2019), pointing to additives as responsible for the toxicity. Toxicity on planktonic marine organisms of some plastic functional additives and cosmetic components at $\mu \mathrm{g} / \mathrm{L} \mathrm{lev-}$ els have been previously reported (Giraldo et al., 2017; Paredes et al., 2014; Tato et al., 2018).

The pharmaceutical industry produces approximately 3000 different synthetic chemicals including antibiotics, painkillers, antidepressants, adrenergic receptor blockers, antidiabetics, contraceptives, and lipid regulators, used to cure, prevent, or alleviate the symptoms of illness (Richardson, 2012). Most of them are used in such low amounts that they do not pose any significant environmental risk, but the most common ones, such as analgesics or psychiatric drugs, have an annual production within the order of 100 to 1000 Ton in Europe (Fent et al., 2006). Anti-inflammatory painkillers such as ibuprofen (IBU), antibiotics such as sulfamethoxazole (SMX), and antidepressants such as fluoxetine (FLU) have been reported to pose a significant environmental risk in aquatic environments (Beiras, 2021; Magureanu et al., 2015).

Personal care products such as shampoos, lotions, and skin-care creams include ingredients intended to inhibit microbial degradation (preservatives), UV filters such as cosmetics octocrylene (OCT) and 4-methylbenzylidene camphor (4-MBC) to prevent photo-oxidation, and fragrances such as galaxolide (HHCB) to provide good smell. In some cosmetics these components reach up to $30-40 \%$ of the final product. Sun screens are specifically used in recreational coastal areas, and swimmers represent a direct input for these substances into the water. Aromatic UV filters are highly lipophilic, with potential for bioaccumulation, and capable to cause endocrine disruption (Fent et al., 2008; Paredes et al., 2014). Maximum concentrations of UV filters in cosmetics in Europe are set in Regulation 1223/2009 (European Commission, 2009) (e.g., 4\% for 4-MBC). In USA, the composition of cosmetics is regulated by (US FDA, 2018), and 4-MBC is not allowed as a sunscreen component.

While many synthetic pesticides and phytosanitary products are regulated and environmental standards are implemented (National acute and chronic water quality criteria from the US Environmental Protection Agency (US EPA, 2021), Canadian water quality guidelines (CCME, 2021), acute and chronic standards for priority pollutants in Directive 2013/39/EU, ANZECC guidelines in Australia and New Zealand (Warne et al., 2018)), BAHC are not included in any of these regulations. Ecotoxicological data obtained from toxicity tests conducted according to standard methods are needed in order to assess the ecological risk of these compounds in coastal environments and to set BAHC water quality criteria on solid scientific grounds. The aim of this study was to advance the standardization of methods intended to the classification of aquatic toxicity of BAHC, and to illustrate these methods with representative BAHC present in plastics, pharmaceuticals, and cosmetic products. In order to maximize the sensitivity of the tests, preference was given to early life stages (embryos and larvae) of the test species, P. lividus (embryos) and A. clausi (larvae) (Durán \& Beiras, 2017). 


\section{Materials and methods}

Test species

Test species were supplied by the Marine Biological Resources Service from ECIMAT (University of Vigo). Tests were conducted in compliance with internationally accepted standard methods. The Paracentrotus lividus sea-urchin embryo test (SET) followed Beiras et al. (2012), and the Acartia sp copepod 48-h survival followed ISO 14669 (ISO, 1999) using nauplius larvae. Briefly, P. lividus gametes were obtained by dissection from conditioned adults; eggs were carefully fertilized in a measuring cylinder adding a few $\mu \mathrm{L}$ of concentrated sperm while gently stirring with a plunger. Fertilization was assessed under a binocular microscope, and 40 fertilized eggs per $\mathrm{mL}$ were delivered for incubation into $4 \mathrm{~mL}$ glass vials with Teflon-lined caps. For copepods, $<24$-h-old nauplii were separated from the adults by using a $40-\mu \mathrm{m}$ metallic mesh and delivered one by one, employing a glass pipette under binocular stereoscope in $10 \mathrm{~mL}$ glass vials. A total of 10 individuals per vial were used. Endpoints recorded after $48 \mathrm{~h}$ were, for sea urchins, length (maximum dimension) in 35 individuals per vial using a Leica DMI 4000B inverted microscope, and for copepods nauplius larvae survival. Further details on the bioassay methods were provided by Tato et al. (2018) and Beiras et al. (2019). All experiments were conducted in isothermal rooms at $20 \pm 0.5^{\circ} \mathrm{C}$.

\section{Experimental solutions}

Toxicity tests were carried out using artificial seawater (ASW) with a defined chemical composition (Lorenzo et al., 2002) and oceanic characteristics $(34 \pm 2$ psu salinity, $8.2 \pm 0.1 \mathrm{pH}, 8.0 \pm 0.2 \mathrm{mg} / \mathrm{L}$ dissolved oxygen). OCT (CAS number: 6197-30-4), BHT (CAS number: 128-37-0), HHCB (CAS number: 122-05-5), 4-MBC (CAS number: 36861-47-9), TDCP (CAS number: 13674-87-8), IBU (CAS number: 15687-27-1), SMX (CAS number: 723-46-6), LAW (CAS number: 83-727), TCPP (CAS number: 13674-84-5), and FLU (CAS number: 56296-78-7) were purchased from SigmaAldrich (Milwaukee, WI, USA) and Merck (Darmstadt, Germany). CHI (CAS number: 192268-64-7) was obtained from AIMPLAS Technological Institute of Plastics (Valencia, Spain).
Based on the water and octanol solubility data of the substances used in this work (Table 1), we propose a decision tree to choose the best available methods for dosage of the chemicals reflected in Fig. S1. For chemicals with a water solubility $\left(S_{\mathrm{w}}\right) \geq 1000 \mathrm{mg} / \mathrm{L}$, stocks were made up in Milli-Q ${ }^{\circledR}$ ultrapure water, and for those with $S_{\mathrm{w}}<1000 \mathrm{mg} / \mathrm{L}$ and solubility in octanol $\geq 1000 \mathrm{mg} / \mathrm{L}$ stocks were made up in dimethylsulfoxide (DMSO). In both cases, serial dilutions of the stock in ASW were tested, up to a final concentration of at least $1 \mathrm{mg} / \mathrm{L}$. Final DMSO concentration in experimental treatments was always below NOEC for both test species: $8.8 \mathrm{~g} / \mathrm{L}$ for P. lividus, and $0.4 \mathrm{~g} / \mathrm{L}$ for $A$. clausi (Tato et al., 2018).

For chemicals with a $S_{\mathrm{w}}<1 \mathrm{mg} / \mathrm{L}$, in addition to the DMSO test, a leachate test was conducted. With that aim, a leachate was obtained using ASW as liquid phase, and serial dilutions were further tested according to the procedures of Tier I in Beiras et al. (2019). The lixiviate was separated from the insoluble chemical by filtering with GF/F (Whatman, Merck, nominal pore $0.7 \mu \mathrm{m}$ ) filters for solid substances and by centrifugation at $2000 \mathrm{rpm}$ for $5 \mathrm{~min}$ for liquid substances. The solid-to-liquid ratio used for preparation of lixiviates was $100 \mathrm{mg} / \mathrm{L}$, the level below which current EU legislation consider a substance as not harmful to aquatic life (European Commission, 2011). In order to assess the effect of the chemical to ASW ratio in the lixiviate on toxicity classification, additional experiments were conducted comparing loads from 0.01 to $10 \mathrm{~g} / \mathrm{L}$ using BHT and $\mathrm{CHI}$ as model substances.

Statistical methods

Statistical analyses were conducted using IBM SPSS statistics software (version 25.0). Larval size for sea urchin and survival for copepod larvae were the endpoints recorded. All data were corrected by the mean control response. Normal distribution and homoscedasticity of the data were checked using the Shapiro-Wilk's and Levene's tests, respectively. When significant differences $(p<0.05)$ among groups were found using ANOVA, then each treatment was compared to the control using Dunnett's post-hoc test to calculate the highest no-observed effect concentration (NOEC) and the lowest observed effect concentration (LOEC). 
Table 1 Toxicity of BAHC used in plastics, cosmetics, and pharmaceuticals on Paracentrotus lividus sea-urchin embryos

\begin{tabular}{|c|c|c|c|c|c|c|c|c|}
\hline \multirow[t]{2}{*}{ Chemical } & \multirow[t]{2}{*}{ CAS-Number } & \multirow[t]{2}{*}{ Use } & \multirow{2}{*}{$\begin{array}{l}\text { Water solubility } \\
(\mathrm{mg} / \mathrm{L})\end{array}$} & \multirow[t]{2}{*}{$\log K_{o w}$} & \multirow[t]{2}{*}{ Test } & \multicolumn{2}{|l|}{ SET } & \multirow{2}{*}{$\begin{array}{l}\text { Acute aquatic } \\
\text { toxicity } \\
(\mathrm{EC} / 1272 / 2008)\end{array}$} \\
\hline & & & & & & $\operatorname{LOEC}(\mu \mathrm{g} / \mathrm{L})$ & $\begin{array}{l}\mathrm{EC}_{10}-\mathrm{CI} 95 \% \\
(\mu \mathrm{g} / \mathrm{L})\end{array}$ & \\
\hline $\begin{array}{l}\text { Fluoxetin } \\
\text { (FLU) }\end{array}$ & $56296-78-7$ & Pharmaceutical & 4000 & 4.05 & Water stock & 30 & $14(6-24)$ & Very toxic \\
\hline \multirow[t]{2}{*}{ TCPP } & \multirow[t]{2}{*}{$13674-84-5$} & \multirow{2}{*}{$\begin{array}{l}\text { Flame retardant } \\
\text { (plastic additive) }\end{array}$} & \multirow[t]{2}{*}{1600} & \multirow[t]{2}{*}{2.59} & Water stock & $>5000$ & n.c. & - \\
\hline & & & & & DMSO stock & $>5000$ & n.c. & - \\
\hline $\begin{array}{l}\text { Sulfamethoxazole } \\
\text { (SFX) }\end{array}$ & $723-46-6$ & Pharmaceutical & 610 & 0.89 & DMSO stock & 5000 & $\begin{array}{l}6134 \\
(4615-11,873)\end{array}$ & Hazardous \\
\hline $\begin{array}{l}\text { Ibuprofen } \\
\text { (IBU) }\end{array}$ & $15687-27-1$ & Pharmaceutical & 21 & 3.97 & DMSO stock & $>10,000$ & n.c. & - \\
\hline TDCPP & $13674-87-8$ & $\begin{array}{l}\text { Flame retardant } \\
\text { (plastic additive) }\end{array}$ & 18.1 & 3.69 & DMSO stock & $>5000$ & n.c. & - \\
\hline $\begin{array}{l}\text { Galaxolide } \\
\text { (HHCB) }\end{array}$ & $122-05-5$ & $\begin{array}{l}\text { Cosmetic } \\
\text { fragrance }\end{array}$ & 1.75 & 5.9 & DMSO stock & 500 & $\begin{array}{c}733(434- \\
1032)\end{array}$ & Toxic \\
\hline 4-MBC & $36861-47-9$ & $\begin{array}{l}\text { Cosmetic UV } \\
\text { filter }\end{array}$ & $0.2-17$ & $4.95-5.92$ & DMSO stock & $600^{(*)}$ & $\begin{array}{l}239(150- \\
343)^{(*)}\end{array}$ & Very toxic \\
\hline $\begin{array}{l}\text { Octocrylene } \\
\text { (OCT) }\end{array}$ & $6197-30-4$ & $\begin{array}{l}\text { Cosmetic UV } \\
\text { filter }\end{array}$ & 0.36 & 6.88 & DMSO stock & - & $162(30-270)$ & Very toxic \\
\hline \multirow{2}{*}{$\begin{array}{l}\text { Chimassorb } \\
\text { (CHI) }\end{array}$} & \multirow[t]{2}{*}{$192268-64-7$} & \multirow{2}{*}{$\begin{array}{l}\text { UV stabilizer } \\
\text { (plastic additive) }\end{array}$} & \multirow[t]{2}{*}{0.2} & \multirow[t]{2}{*}{-} & DMSO stock & $>300$ & n.c. & - \\
\hline & & & & & Lixiviate & $>1 * 10^{5}$ & n.c. & Non-toxic \\
\hline \multirow[t]{2}{*}{ BHT } & \multirow[t]{2}{*}{$128-37-0$} & \multirow{2}{*}{$\begin{array}{l}\text { Antioxidant } \\
\text { (plastic additive) }\end{array}$} & \multirow[t]{2}{*}{0.4} & \multirow[t]{2}{*}{5.1} & DMSO stock & 100 & $91(57-121)$ & Very toxic \\
\hline & & & & & Lixiviate & $1 * 10^{5}$ & $3.6 * 10^{4}$ (n.c.) & Non-toxic \\
\hline \multirow[t]{2}{*}{$\begin{array}{l}\text { Lawsone } \\
\text { (LAW) }\end{array}$} & \multirow[t]{2}{*}{$83-72-7$} & \multirow[t]{2}{*}{ Antimicrobial } & \multirow[t]{2}{*}{$0.2-<1000$} & \multirow[t]{2}{*}{$1.38-4.1^{\mathrm{a}}$} & DMSO stock & 9000 & $\begin{array}{l}13,821 \\
(9614-20,904)\end{array}$ & Non-toxic \\
\hline & & & & & Lixiviate & 33333 & 24,636 (n.c.) & Non-toxic \\
\hline
\end{tabular}

The substances were tested by means of serial dilutions of a stock dissolved in ultrapure water, a stock dissolved in DMSO, or a $0.1 \mathrm{~g} / \mathrm{L}$ lixiviate. Lowest observed effect concentration (LOEC) for BAHC. EC $_{10}$ for all compounds and $95 \%$ confidence intervals given in brackets. Lowest observed effect concentration (LOEC) levels for all the compounds. In the table, n.c. means "not calculated". Water solubility and $K_{\mathrm{ow}}$ data were obtained from https://pubchem.ncbi.nlm.nih.gov/ except when otherwise stated.

*Data from Paredes et al. (2014)

${ }^{a}$ From: https://www.parchem.com/chemical-supplier-distributor/Lawsone-042337.aspx

Non-parametric tests, Kruskall-Wallis, and Mann Whitney U were used when data did not meet the requirements for parametric tests. The $\mathrm{EC}_{50}$ and $\mathrm{EC}_{10}$ values and their $95 \%$ confidence intervals were calculated by using a Probit non-linear regression model. In lixiviate tests, toxic units (TU) were defined as the dilution factor of the lixiviate that causes a $50 \%$ effect on the endpoint. The sensitivity of the two biological models (sea urchins and copepods) to BAHCs was compared by fitting the $\mathrm{EC}_{50}$ values to a linear correlation model and testing whether the slope is significantly different to 1 .

\section{Results and discussion}

Toxicity tests using stock dilutions

As reflected in Table 1, the most toxic BAHC tested was FLU $\left(\mathrm{EC}_{10}=14 \mu \mathrm{g} / \mathrm{L}, 95 \%\right.$ confidence interval 6-24) followed by BHT $\left(\mathrm{EC}_{10}=91 \mu \mathrm{g} / \mathrm{L}, 57-121\right)$, OCT $\left(\mathrm{EC}_{10}=162 \mu \mathrm{g} / \mathrm{L}, 567-1091\right)$, and 4-MBC $\left(\mathrm{EC}_{10}=239 \mu \mathrm{g} / \mathrm{L}, 150-343\right)$. These chemicals can be classified as very toxic to aquatic life according to Regulation No 286/2011 (European Commission, 2011), since their $\mathrm{EC}_{50}$ was lower than $1 \mathrm{mg} / \mathrm{L}$ (see 
Table 1). The ranking of toxicity decreases with HHCB $\left(\mathrm{EC}_{10}=733 \mu \mathrm{g} / \mathrm{L}, 434-1032\right)$, which can be classified as toxic $\left(\mathrm{EC}_{50}=1276 \mu \mathrm{g} / \mathrm{L}, 1065-1486\right)$, SUL $\left(\mathrm{EC}_{10}=6.1 \mathrm{mg} / \mathrm{L}, 4.6-11.8\right)$, and LAW $\left(\mathrm{EC}_{10}=13.8 \mathrm{mg} / \mathrm{L}, 9.6-20.9\right)$. IBU and the plastic additives TDCP, TCPP, and CHI were the least toxic chemicals tested.

The A. clausi test yielded a slightly different ranking, with toxicity decreasing in the order OCT $\left(\mathrm{EC}_{10}=13 \mu \mathrm{g} / \mathrm{L}, 95 \%\right.$ confidence interval not calculable, n.c.), FLU ( $\mathrm{EC}_{10}=34 \mu \mathrm{g} / \mathrm{L}$, n.c.), 4-MBC $\left(\mathrm{EC}_{10}=39 \mu \mathrm{g} / \mathrm{L}, 4-76\right), \mathrm{BHT}\left(\mathrm{EC}_{10}=78 \mu \mathrm{g} / \mathrm{L} .8-117\right)$, TDCP $\left(\mathrm{EC}_{10}=126\right)$, and LAW $\left(\mathrm{EC}_{10}=1909 \mu \mathrm{g} / \mathrm{L}\right.$, n.c.). Therefore, sea urchin larvae were more sensitive to FLU than A. clausi nauplii, whereas OCT, 4-MBC, TDCP, and LAW affected more the copepod than the sea-urchin larvae. However, it is remarkable that both tests produce consistent classifications; OCT, FLU, 4-MBC, and BHT, when tested with Acartia, would be classified again as very toxic, whereas LAW would be classified just as hazardous to aquatic life. In contrast, TDCP seems to have a more specific mode of action affecting crustaceans but not echinoderms.

When results from laboratory toxicity tests using single substances in chemically defined water are used to derive environmental standards, we must take into account the potential effects of humic substances with the ability to complex toxic molecules, as well as the potential interactions among chemicals that may take place in more complex environmental scenarios.

\section{Comparison of stock dilution vs lixiviates}

For highly hydrophobic chemicals $\left(S_{\mathrm{w}}<1 \mathrm{mg} / \mathrm{L}\right)$, the toxicity obtained from testing serial dilutions of the DMSO stock was compared with that of lixiviates obtained by mixing the substance in ASW at a $100 \mathrm{mg}$ per litter solid-to-liquid ratio for $24 \mathrm{~h}$ (Table 1). For the antimicrobial LAW, larval size increased as the lixiviate was diluted according to a dose:response pattern (Fig. 1c) from which a TU value of $1.23(0.92-1.53)$ was obtained. This would correspond to an $\mathrm{EC}_{50}$ value of $100 / 1.23=81.3 \mathrm{mg} / \mathrm{L}$. In the DMSO stock test, the $\mathrm{EC}_{10}$ was $13.8 \mathrm{mg} / \mathrm{L}$ but the $\mathrm{EC}_{50}$ could not be calculated since growth inhibition was lower than $50 \%$ at the higher concentration tested. However, a rough estimation of the $\mathrm{EC}_{50}$ can be obtained from the average $\mathrm{EC}_{50} / \mathrm{EC}_{10}$ ratio of 3.3 compiled from similar tests by Durán and Beiras (2017). This value is $45.6 \mathrm{mg} / \mathrm{L}$, within the same order of magnitude than that obtained from the lixiviate test $(81.3 \mathrm{mg} / \mathrm{L})$, and in both cases classifying LAW within the category of substances hazardous to aquatic life $\left(10<\mathrm{EC}_{50} \leq 100 \mathrm{mg} / \mathrm{L}\right)$.

In contrast, for BHT, large discrepancies in toxicity classification were obtained depending on the method of dosage, with the lixiviate method failing to detect any toxicity $\left(\mathrm{EC}_{50}>100 \mathrm{mg} / \mathrm{L}\right)$ whereas the DMSO stock method classifies this substance as very toxic disregarding the test species used. The role of the organic carrier as vehicle of BHT seems to largely enhance the toxicity of this highly hydrophobic substance compared to exposure to the aqueous lixiviate. While the precautionary principle would support the use of the DMSO stock method, a more environmentally realistic estimation of risk would opt for the lixiviate method (see next section also).

\section{Solid-to-liquid ratio for lixiviation}

For the highly hydrophobic chemicals CHI and BHT, the toxicity of leachates obtained using different solid-to-liquid ratios, from 0.01 to $10 \mathrm{~g} / \mathrm{L}$ in $\times 10$ geometric sequence was compared using the sea-urchin test (Fig. 1). CHI (Fig. 1a) was consistently classified as non-toxic regardless the ratio used, although the lowest larval size was recorded in the undiluted leachate with the highest solid-to-liquid ratio, $10 \mathrm{~g} / \mathrm{L}$. On the other hand, BHT (Fig. 1b) showed toxicity, i.e., caused a significant decrease in larval size, in all undiluted leachates tested.

However, once toxicity is expressed in TU, no comparisons can be made among lixiviates obtained using different solid-to-liquid ratio. As expected from the low solubility of the chemical, higher amounts of substance used to make up the lixiviate fail to achieve a proportional increase in the lixiviate toxicity, expressed in TU. A tenfold increase in $\mathrm{g} / \mathrm{L}$ produced on average just a 1.4-fold increase in TU.

Therefore, despite working with chemical loads orders of magnitude above their theoretical water solubility, lixiviates obtained at higher solid-to-liquid ratios were more toxic to the larvae. This suggests that part of the non-dissolved chemical is accommodated into the liquid phase and becomes partly bioavailable when the lixiviate is diluted.

These differences in toxicity among lixiviates obtained at different solid-to-liquid ratios stress the 

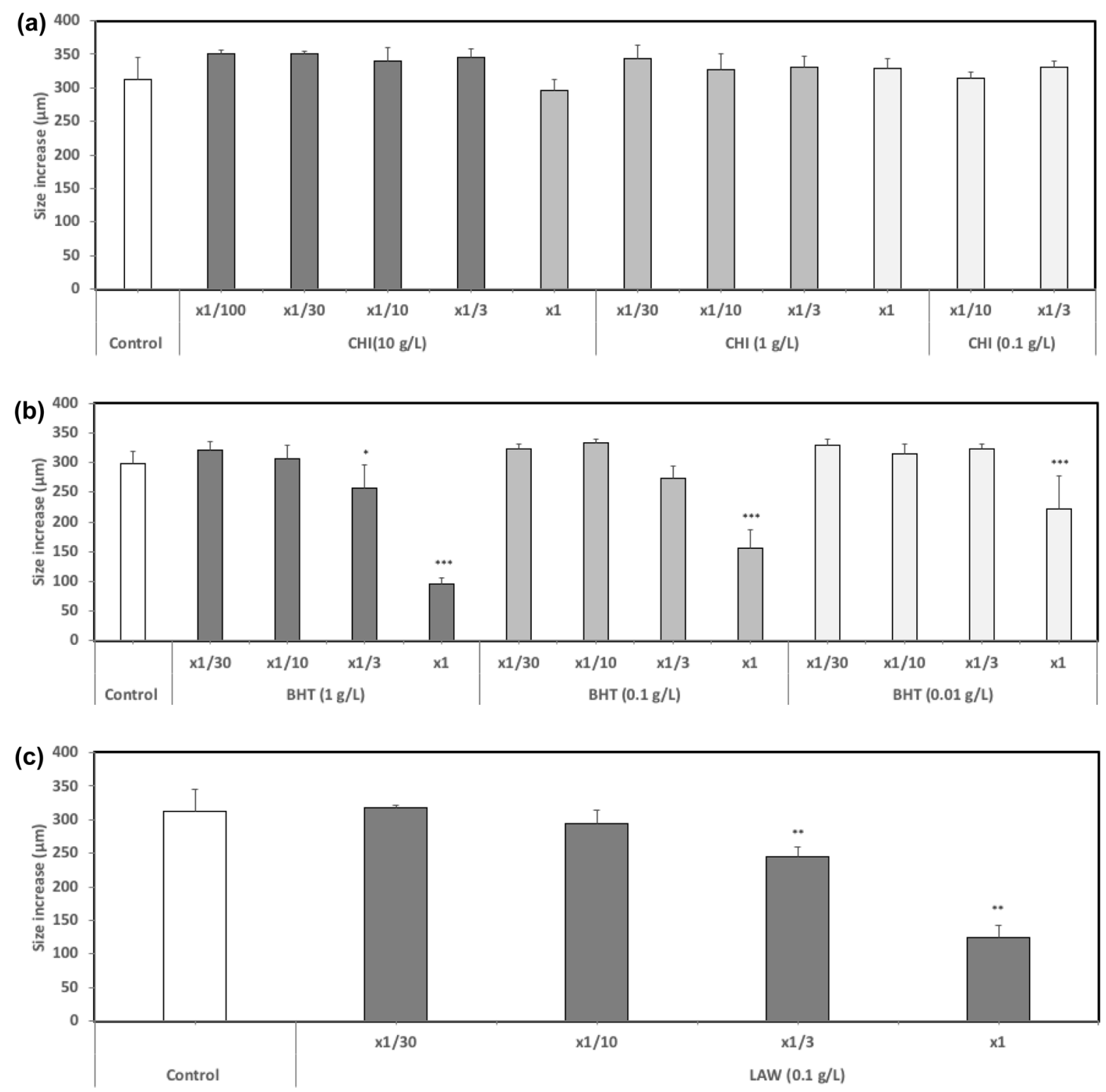

Fig. $1 P$. lividus larval size increases, in serial dilutions $(\times 1 / 30, \times 1 / 10, \times 1 / 3, \times 1)$ of CHI $(\mathbf{a})$, BHT $(\mathbf{b})$, and LAW (c) leachates in ASW. The different solid-to-liquid ratios $(\mathrm{g} / \mathrm{L})$

need for methodological standardization. Toxicity data can, thus, be compared only when lixiviation is conducted using the same solid-to-liquid ratio. Lower ratios decrease the limit of detection of toxicity, whereas higher ratios may underestimate TU values, require high amounts of pure chemicals, and produce more toxic used to make up the leachates are indicated. Bars represent mean $\pm \mathrm{SD}(N=4)$. Asterisks refer to significant differences to control (Control) $* p<0.05, * * p<0.01$ and $* * * p<0.001$

waste. A solid-to-liquid ratio of $0.1 \mathrm{~g} / \mathrm{L}$, i.e., $100 \mathrm{mg} / \mathrm{L}$, seems to balance sensitivity, environmental relevance, and feasibility, and allows results to be useful for classification of substances according to their aquatic toxicity, since $100 \mathrm{mg} / \mathrm{L}$ is the $\mathrm{EC}_{50}$ threshold above which substances are considered as not hazardous. 
Fig. $2 \mathrm{EC}_{50}$ values $(\mu \mathrm{g} / \mathrm{L})$ of different chemicals recorded in 48-h tests using larvae of Acartia spp and Paracentrotus lividus (Table S2). Notice that Acartia values are lower, indicating a higher sensitivity, reflected also in the slope $<1$ of the linear correlation equation

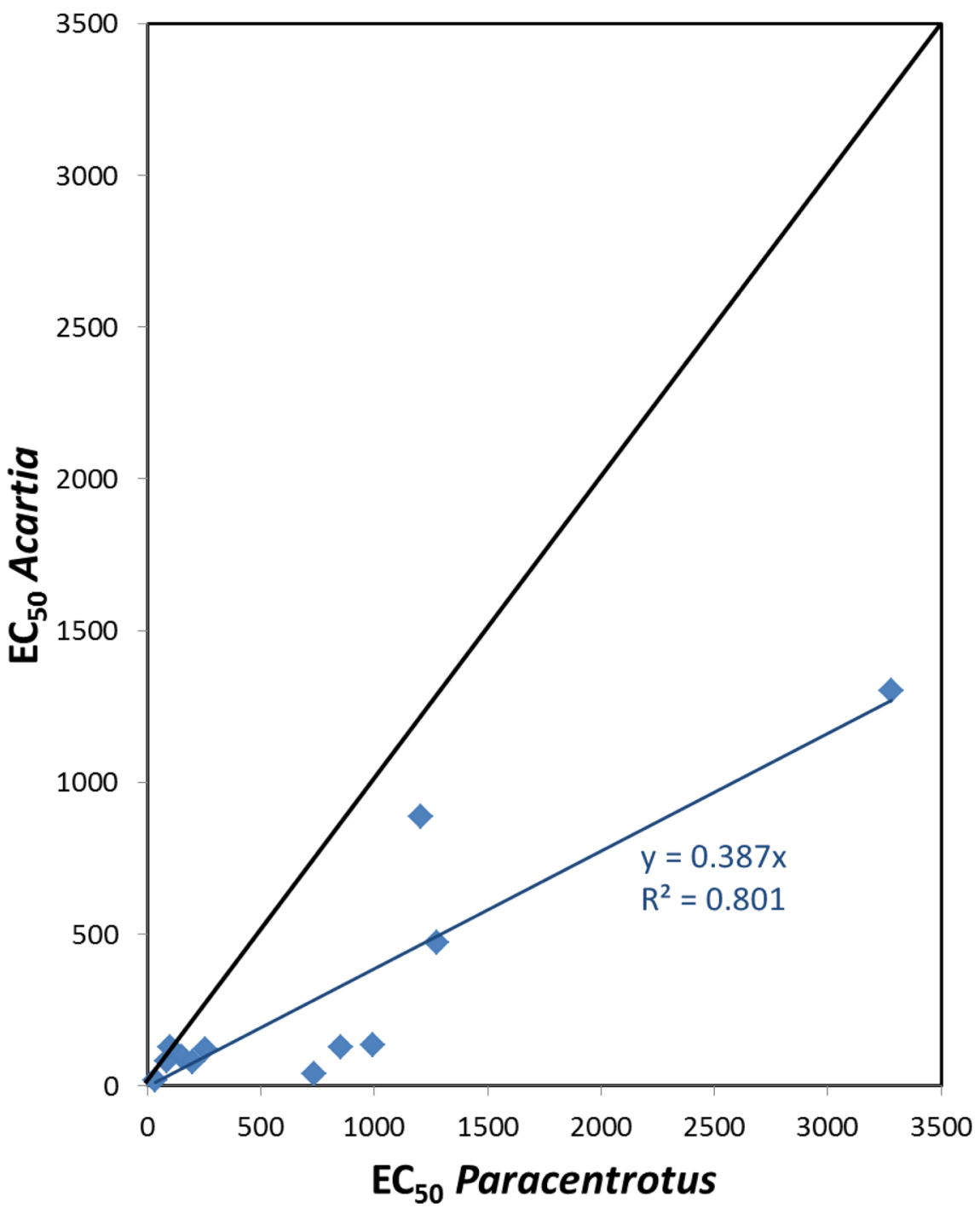

Comparison among aquatic test species

While metals, polyaromatic hydrocarbons, and some pesticides are regulated and water quality standards are available world-wide, BAHC lack environmental standards, which can only be implemented on the basis of sound ecotoxicological information using standardized procedures (Beiras \& Schönemann, 2021, and citations therein). Table S1 compares the toxicity thresholds found in the present study with those previously reported for other marine test species. This information provides the grounds for derivation of marine water quality criteria for these emerging pollutants, currently not included in environmental regulations. The toxicity found with sea-urchin larvae is also similar to acute toxicity reported for the standard freshwater model Daphnia. For example, HHCB showed on $P$. lividus an $\mathrm{EC}_{50}=1276 \mu \mathrm{g} / \mathrm{L}$, similar to that previously reported on D. magna with a $48 \mathrm{~h}-\mathrm{LC}_{50}$ of $1170 \mu \mathrm{g} / \mathrm{L}$ (Chen et al., 2015) and $2684 \mu \mathrm{g} / \mathrm{L}$ (Fan et al., 2019).

In contrast, the nauplius larvae of the marine copepod Acartia seems to be more sensitive than other aquatic test species. Figure 2 compares the sensitivity to organic and metallic toxicants, in terms of 48-h $\mathrm{EC}_{50}$, between sea urchin and Acartia larvae. For 11 of the 12 chemicals reviewed, the Acartia $\mathrm{EC}_{50}$ value was lower, which reflects in a slope significantly lower than 
1 in the equation of the linear correlation Acartia $\mathrm{EC}_{50}$ vs Paracentrotus $\mathrm{EC}_{50}(\mathrm{~b}=0.39$; 95\% CI 0.26-0.53).

Acartia nauplii seem also more sensitive than the standard freshwater model Daphnia. Fent et al. (2010) found an acute $\mathrm{LC}_{50}$ for $4-\mathrm{MBC}$ in D. magna of $560 \mu \mathrm{g} / \mathrm{L}$, whereas in our experiment, $A$. clausi showed a LC 50 of $127 \mu \mathrm{g} / \mathrm{L}$. Nielsen and Roslev (2018) reported an $\mathrm{EC}_{50}$ value of $2290 \mu \mathrm{g} / \mathrm{L}$ of FLU on D. magna mobility, remarkably higher that Acartia's $\mathrm{LC}_{50}$ of $128 \mu \mathrm{g} / \mathrm{L}$. Wollenberger et al. (2003) reported for Acartia tonsa exposed to $\mathrm{HCCB}$ an $\mathrm{EC}_{10}$ of $37 \mu \mathrm{g} / \mathrm{L}$ markedly lower than Daphnia's LOEC [205 $\mu \mathrm{g} / \mathrm{L}$, cited by Balk and Ford (1999)].

\section{Conclusions}

Common everyday household chemicals such the antioxidant BHT, the UV filters broadly present in cosmetics OCT and 4-MBC, or the pharmaceutical FLU, are consistently classified as very toxic to aquatic life according to their toxicity to early life stages of marine invertebrates. These findings stress the need to develop water quality criteria for these chemicals on the basis of standard toxicity testing procedures. We provide a protocol for testing based on water solubility and $K_{\text {ow }}$ in order to achieve comparable toxicity parameters useful for the classification of household chemicals and derivation of environmental quality criteria and standards for these emerging pollutants. The use of Acartia nauplii in this protocol provides high sensitivity and, thus, protective value to the toxicity values obtained according to the present protocol.

Acknowledgements This work was funded by the Spanish Government through Research Projects ARPA-ACUA (CTM2016-77945-C3) and ECOPLAS (PID2019-108857RBC3), and by the Galician Government (Xunta de Galicia) through "Grupos de Referencia Competitiva" ED431C 2017/46. I acknowledge the technical assistance of Mar González, Pedro Campoy-López and Alejandro Vilas.

Funding Open Access funding provided thanks to the CRUE-CSIC agreement with Springer Nature.

Data availability Data, associated meta-data, and calculation tools are available from the corresponding author (rbeiras@ uvigo.gal).

Open Access This article is licensed under a Creative Commons Attribution 4.0 International License, which permits use, sharing, adaptation, distribution and reproduction in any medium or format, as long as you give appropriate credit to the original author(s) and the source, provide a link to the Creative
Commons licence, and indicate if changes were made. The images or other third party material in this article are included in the article's Creative Commons licence, unless indicated otherwise in a credit line to the material. If material is not included in the article's Creative Commons licence and your intended use is not permitted by statutory regulation or exceeds the permitted use, you will need to obtain permission directly from the copyright holder. To view a copy of this licence, visit http://creativecommons.org/licenses/by/4.0/.

\section{References}

Balk, F., \& Ford, R. A. (1999). Environmental risk assessment for the polycyclic musks AHTN and HHCB in the EU. I. Fate and exposure assessment. Toxicology Letters, 111(1-2), 57-79. https://doi.org/10.1016/S0378-4274(99) 00169-1

Beiras, R. (2018). Marine Pollution. Sources, fate and effects of pollutants in coastal ecosystems. Elsevier.

Beiras, R. (2021). Environmental risk assessment of pharmaceutical and personal care products in estuarine and coastal waters. In J. C. Durán-álvarez \& B. Jiménezcisneros (Eds.), Pharmaceuticals in marine and coastal environments occurrence, effects, and challenges in a changing world (pp. 195-252). Elsevier.

Beiras, R., Bellas, J., Cachot, J., Cormier, B., Cousin, X., Engwall, M., et al. (2018). Ingestion and contact with polyethylene microplastics does not cause acute toxicity on marine zooplankton. Journal of Hazardous Materials, 360(July), 452460. https://doi.org/10.1016/j.jhazmat.2018.07.101

Beiras, R., Durán, I., \& Bellas, J. (2012). Biological effects of contaminants: Paracentrotus lividus sea urchin embryo test with marine sediment elutriates. ICES Techniques in Marine Environmental Sciences, 51, 13.

Beiras, R., \& Schönemann, A. M. (2021). Water quality criteria for selected pharmaceuticals and personal care products for the protection of marine ecosystems. Science of the Total Environment, 758, 143589. https://doi.org/10.1016/j. scitotenv.2020.143589

Beiras, R., Tato, T., \& López-Ibáñez, S. (2019). A 2-Tier standard method to test the toxicity of microplastics in marine water using Paracentrotus lividus and Acartia clausi larvae. Environmental Toxicology and Chemistry, 38(3), 630-637. https://doi.org/10.1002/etc.4326

Bejgarn, S., MacLeod, M., Bogdal, C., \& Breitholtz, M. (2015). Toxicity of leachate from weathering plastics: An exploratory screening study with Nitocra spinipes. Chemosphere, 132, 114-119. https://doi.org/10.1016/j. chemosphere.2015.03.010

Bolgar, M., Hubball, J., Groeger, J., \& Meronek, S. (2015). Handbook for the chemical analysis of plastic and polymer additives (2nd ed.). CRC Press. https://doi.org/10. 1201/b19124

British Plastic Federation. (2021). Plastics additives. https:// www.bpf.co.uk/plastipedia/additives/default.aspx. Accessed 21 August 2021.

CCME. (2021). Canadian environmental quality guidelines. https://ccme.ca/en/summary-table. Accessed 21 August 2021.

Chen, F., Yao, Q., \& Zhou, X. (2015). The influence of suspended solids on the combined toxicity of galaxolide and 
lead to Daphnia magna. Bulletin of Environmental Contamination and Toxicology, 95(1), 73-79. https://doi.org/ 10.1007/s00128-015-1543-3

Cole, M., Lindeque, P., Fileman, E., Halsband, C., \& Galloway, T. S. (2015). The impact of polystyrene microplastics on feeding, function and fecundity in the marine copepod Calanus helgolandicus. Environmental Science and Technology, 49(2), 1130-1137. https://doi.org/10.1021/es504525u

Durán, I., \& Beiras, R. (2017). Acute water quality criteria for polycyclic aromatic hydrocarbons, pesticides, plastic additives, and 4-Nonylphenol in seawater. Environmental Pollution, 224, 384-391. https://doi.org/10.1016/j.envpol.2017.02.018

European Commission. (2009). REGULATION (EC) No 1223/2009 OF THE EUROPEAN PARLIAMENT AND OF THE COUNCIL of 30 November 2009 on cosmetic products. https://eur-lex.europa.eu/eli/reg/2009/1223/oj. Accessed 10 January 2021.

European Commission. (2011). Commission Regulation (EU) No 286/2011 of 10 March 2011 amending, for the purposes of its adaptation to technical and scientific progress, Regulation (EC) No 1272/2008 of the European Parliament and of the Council on classification, labelling and packagin. https://eur-lex.europa.eu/legal-content/EN/ TXT/?uri=CELEX\%3A32011R0286. Accessed 10 January 2021.

Fan, B., Wang, X., Li, J., Gao, X., Li, W., Huang, Y., \& Liu, Z. (2019). Deriving aquatic life criteria for galaxolide (HHCB) and ecological risk assessment. Science of the Total Environment, 681, 488-496. https://doi.org/10. 1016/j.scitotenv.2019.05.033

Fent, K., Kunz, P. Y., \& Gomez, E. (2008). UV filters in the aquatic environment induce hormonal effects and affect fertility and reproduction in fish. Chimia, 62(5), 368-375. https://doi.org/10.2533/chimia.2008.368

Fent, K., Kunz, P. Y., Zenker, A., \& Rapp, M. (2010). A tentative environmental risk assessment of the UV-filters 3-(4-methylbenzylidene-camphor), 2-ethyl-hexyl-4trimethoxycinnamate, benzophenone-3, benzophenone-4 and 3-benzylidene camphor. Marine Environmental Research, 69(Suppl. 1), S4-S6. https://doi.org/ 10.1016/j.marenvres.2009.10.010

Fent, K., Weston, A. A., \& Caminada, D. (2006). Ecotoxicology of human pharmaceuticals. Aquatic Toxicology, 76(2), 122-159. https://doi.org/10.1016/j.aquatox.2005.09.009

Giraldo, A., Montes, R., Rodil, R., Quintana, J. B., Vidal-Liñán, L., \& Beiras, R. (2017). Ecotoxicological evaluation of the UV filters ethylhexyl dimethyl p-aminobenzoic acid and octocrylene using marine organisms Isochrysis galbana, Mytilus galloprovincialis and Paracentrotus lividus. Archives of Environmental Contamination and Toxicology, 72(4), 606-611. https://doi.org/10.1007/s00244-017-0399-4

Hahladakis, J. N., Velis, C. A., Weber, R., Iacovidou, E., \& Purnell, P. (2018). An overview of chemical additives present in plastics: Migration, release, fate and environmental impact during their use, disposal and recycling. Journal of Hazardous Materials, 344, 179-199. https:// doi.org/10.1016/j.jhazmat.2017.10.014

ISO. (1999). Water quality-determination of acute lethal toxicity to marine copepods (Copepoda, Crustacea). ISO 14669:1999(E). International Organization for Standardization, Genève, Switzerland. 16 pp. https://www.iso.org/standard/25162.html
Kaposi, K. L., Mos, B., Kelaher, B. P., \& Dworjanyn, S. A. (2014). Ingestion of microplastic has limited impact on a marine larva. Environmental Science and Technology, 48(3), 1638-1645. https://doi.org/10.1021/es404295e

Lithner, D., Damberg, J., Dave, G., \& Larsson, Å. (2009). Leachates from plastic consumer products: Screening for toxicity with Daphnia magna. Chemosphere, 74(9), 11951200. https://doi.org/10.1016/j.chemosphere.2008.11.022

Lithner, D., Nordensvan, I., \& Dave, G. (2012). Comparative acute toxicity of leachates from plastic products made of polypropylene, polyethylene, PVC, acrylonitrile-butadiene-styrene, and epoxy to Daphnia magna. Environmental Science and Pollution Research, 19(5), 1763-1772. https://doi.org/10. 1007/s11356-011-0663-5

Lorenzo, J. I., Nieto, O., \& Beiras, R. (2002). Effect of humic acids on speciation and toxicity of copper to. Aquatic Toxicology, 58, 27-41.

Magureanu, M., Mandache, N. B., \& Parvulescu, V. I. (2015). Degradation of pharmaceutical compounds in water by non-thermal plasma treatment. Water Research, 81, 124136. https://doi.org/10.1016/j.watres.2015.05.037

Margot, J., Rossi, L., Barry, D. A., \& Holliger, C. (2015). A review of the fate of micropollutants in wastewater treatment plants. Wires Water, 2(5), 457-487. https://doi.org/ $10.1002 /$ wat 2.1090

Nielsen, M. E., \& Roslev, P. (2018). Behavioral responses and starvation survival of Daphnia magna exposed to fluoxetine and propranolol. Chemosphere, 211, 978-985. https:// doi.org/10.1016/j.chemosphere.2018.08.027

Oliviero, M., Tato, T., Schiavo, S., Fernández, V., Manzo, S., \& Beiras, R. (2019). Leachates of micronized plastic toys provoke embryotoxic effects upon sea urchin Paracentrotus lividus. Environmental Pollution, 247, 706-715. https://doi.org/10.1016/j.envpol.2019.01.098

Paredes, E., Perez, S., Rodil, R., Quintana, J. B., \& Beiras, R. (2014). Ecotoxicological evaluation of four UV filters using marine organisms from different trophic levels Isochrysis galbana, Mytilus galloprovincialis, Paracentrotus lividus, and Siriella armata. Chemosphere, 104, 44-50. https://doi. org/10.1016/j.chemosphere.2013.10.053

Plastics Europe, G. M. R., \& Conversio Market \& Strategy GmbH. (2020). Plastics-the facts 2020. https://www. plasticseurope.org/en/resources/market-data. Accessed 10 Jan 2021.

Richardson, S. D. (2012). Environmental mass spectrometry: Emerging contaminants and current issues. Analytical Chemistry, 84(2), 747-778. https://doi.org/10.1021/ac202903d

Samchetshabam, G., Choudhury, T. G., \& Gita, S. (2017). Impact of textile dyes waste on aquatic environments and its treatment wastewater management view project tribal sub plan view project. Environment \& Ecology, 35(September), 2349-2353.

Tato, T., Salgueiro-González, N., León, V. M., González, S., \& Beiras, R. (2018). Ecotoxicological evaluation of the risk posed by bisphenol A, triclosan, and 4-nonylphenol in coastal waters using early life stages of marine organisms (Isochrysis galbana, Mytilus galloprovincialis, Paracentrotus lividus, and Acartia clausi). Environmental Pollution, 232, 173-182. https://doi.org/10.1016/j.envpol.2017.09.031

US FDA. (2018). Federal food, drug, and cosmetic act. https:// www.fda.gov/regulatory-information/laws-enforced-fda/ 
federal-food-drug-and-cosmetic-act-fdc-act. Accessed 10 January 2021.

US EPA. (2021). National recommended water quality criteria. https://www.epa.gov/wqc/national-recommended-waterquality-criteria. Accessed 10 January 2021.

Vroom, R. J. E., Koelmans, A. A., Besseling, E., \& Halsband, C. (2017). Aging of microplastics promotes their ingestion by marine zooplankton. Environmental Pollution, 231, 987-996. https://doi.org/10.1016/j.envpol.2017.08.088

Warne, M. S. J., Batley, G., van Dam, R., Chapman, J., Fox, D., Hickey, C., \& Stauber, J. (2018). Revised method for deriving Australian and New Zealand water quality guideline values for toxicants. Department of Science, Information Technology, Innovation for the Arts (QLD, AU), (August 2018). https://doi.org/10.13140/RG.2.2.36577.35686

Wollenberger, L., Breitholtz, M., Kusk, K. O., \& Bengtsson, B. E. (2003). Inhibition of larval development of the marine copepod Acartia tonsa by four synthetic musk substances. Science of the Total Environment, 305(1-3), 53-64. https://doi.org/10.1016/S0048-9697(02)00471-0

Publisher's Note Springer Nature remains neutral with regard to jurisdictional claims in published maps and institutional affiliations. 